\title{
Informal urban green space as anti-gentrification strategy?
}

\author{
Christoph D. D. Rupprecht* \\ FEAST Project, Research Institute for Humanity and Nature, Kyoto, Japan \\ crupprecht@.chikyu.ac.jp
}

Jason A. Byrne
Environmental Futures Research Institute and Griffith School of Environment,
Griffith University, Gold Coast, Australia

Note: This manuscript represents a preprint version of a book chapter. The book chapter has been accepted to be published as part of the book Just Green Enough.

\begin{abstract}
Access to urban greenspace is vital for urban residents' wellbeing. Yet investment in new parks can trigger housing price inflation through a process termed environmental gentrification. This can in turn potentially displace marginalized and vulnerable residents. In this chapter, we examine cases from Japan and Australia, investigating how informal urban greenspaces (IGS) (e.g. vacant lots, street or railway verges, brownfields, and power line corridors) could function as an 'anti-gentrification' urban greening strategy. Employing conceptual insights from political ecology and environmental justice, we use spatial and statistical analysis to test whether IGS is socio-spatially differentiated by (dis)advantage, and whether factors such as income and education affect residents' perception and use of IGS. Results suggest that IGS holds considerable potential as a 'just green enough' intervention, because it does not appear to trigger gentrification as occurs with more 'intentional' green spaces. We argue that a key difference between intentional and informal greenspaces is the apparent empowerment of residents as co-creators, designers, managers and users of greenspace - not as passive consumers. Informal greenspaces may thus fulfill recreational needs while avoiding demands for a 'return on investment', a driver of environmental-gentrification. Insights from Japan suggest that planners and urban managers should identify and reduce IGS use barriers, provide better information (e.g. IGS maps), and work with residents to promote its use.
\end{abstract}

Keywords: derelict land; urban agriculture; environmental justice; political ecology; participatory management; eco-gentrification 


\section{Introduction}

Urban greening initiatives are underway in many cities internationally, intended to address issues associated with global environmental change (Brink et al. 2016). Urban greening has diverse drivers, scaling-up from the local to the global, including climate change, food security, mass migration, and rapid urbanization (Wolch et al. 2014). Urban greening activities also respond to revitalization initiatives (to attract new investment) and sometimes to community demands for better greenspace access. Greenspace accessibility is seldom uniform across urban areas and is typically sociospatially differentiated (Rutt and Gulsrud 2016).

Histories of discrimination and unfair land use planning and land development practices can produce urban landscapes bereft of formal greenspace (Byrne and Wolch 2009). Over the past two decades, international research has found inequalities in the sociospatial distribution of parks, recreation areas and urban forests (Anguelovski 2016). Levels of maintenance, facilities provision, variety of programming, crowding levels, and policing are oftentimes differentiated by socio-demographic characteristics (e.g. race, ethnicity, class, gender and (dis)ability) (Sister et al. 2010). Marginalized and disadvantaged communities tend to have lower levels of facilities provision and less access to formal greenspaces (e.g. parks, greenways, botanic gardens etc). Researchers have also identified psychological barriers to greenspace access, which can negatively impact diverse communities (Shackleton and Blair 2013). Urban greening has become an environmental justice concern.

Recently, some researchers have observed that urban greening can trigger 'environmental-gentrification', further entrenching environmental inequalities (Checker 2011, Eckerd 2011, Kern 2015, Pearsall 2010). Environmental-gentrification occurs when the conversion of brownfields to greenspace, provision of new greenspace, or redevelopment of existing greenspace drives-up property values, because a location becomes more attractive to investors and/or more desirable for residents (Millington 2015, Quastel 2009). Increased desirability is partly attributable to the multiple ecosystem services and functions of greenspace (e.g. heat attenuation, storm-water interception, pollution reduction) and concomitant benefits that urban greening can confer upon urban residents (e.g. increased physical activity, improved mental health, improved property values) (Rutt and Gulsrud 2016). This begs the question: 'what actions might be undertaken to redress the environmental-gentrification that accompanies greenspace provision?'. Commentators have suggested interventions such as rent control, additional park provision or even environmental offsets (e.g. green roofs) (Wolch et al. 2014), but less attention has been given to the possibility of activating other urban spaces in what might be thought of as a 'just green enough' strategy (Curran and Hamilton 2012). Informal greenspace is an example.

Informal urban greenspaces (IGS) such as vacant lots, street or railway verges, brownfields, and powerline corridors (Figure 1), are receiving renewed attention from researchers and greenspace planners alike (Rupprecht and Byrne 2014a, Rupprecht and Byrne 2014b, Rupprecht et al. 2015, Rupprecht et al. 2016). In contrast to formal greenspaces, informal greenspaces have not been intentionally designed for parks, open space, recreation or community agriculture; rather the opposite. Informal greenspaces occur where a landowner's ambivalence or neglect has been exploited by (non)human agents, for instance where spontaneous vegetation (e.g. weeds) colonizes a site and attracts animals and people. Arguably, informal urban greenspace might better answer 
the needs of some urban residents, because it does not embody a particular cultural politics of nature. Scholars have noted that parks and gardens oftentimes instantiate philosophies of nature that undergird and ligitimize particular socio-cultural projects (e.g. moral uplift, citizen fitness) (Byrne 2012). Indeed, Nohl $(1990,65)$ has asserted that informal greenspace provides the potential for a 'provisional arrangement' that leaves room for both emancipated greenspace users and nonhumans because 'it disciplines neither people in their actions nor nature in its development.'

In this chapter, we draw upon political ecology and environmental justice perspectives to examine whether informal urban greenspaces (IGS) such as vacant lots, street or railway verges, brownfields, and power line corridors could meet residents' greenspace needs without triggering gentrification. Taking a cue from (Curran \& Hamilton 2012, 1030), we ask 'how might alternative greenspace and/or green infrastructure 'complicate gentrification and neoliberalisation'? Based on fieldwork in Japan and Australia we examine the location of IGS, its use by residents, and its potential impact on property values. We conclude that the IGS we have assessed does not exhibit the same patterns of socio-spatial (dis)advantage reported for many public parks. IGS appears to fulfill the needs of different types of urban residents while avoiding the financial demands of formal greenspace, which may require a 'return on investment' (e.g. via property (re)development) thus potentially avoiding environmental gentrification.

\section{Political ecology(ies) of just urban greenspace}

Urban greening can improve cities by meeting residents diverse recreational needs (Lin et al. 2015), cooling ambient temperatures (Byrne et al. 2016), intercepting urban storm water (Fitzgerald and Laufer 2016) and providing spaces for locally-grown food (Lafontaine-Messier et al. 2016). While urban greening offers manifold benefits, some scholars contend that we need 'more democratic, diverse and just' greenspaces in cities (Curran \& Hamilton 2012, 1039). Formal greenspace acquisition and management can create administrative challenges (e.g. safety concerns, increased crime, property impacts, maintenance burdens etc.) (Sreetheran and van den Bosch 2014). And greenspace planning may perpetuate existing environmental inequalities and create new ones (Anguelovski 2016).

Marginalized and vulnerable people tend to be disproportionately exposed to environmental harm in cities and typically have less access to environmental benefits, including greenspaces (Checker 2011). But efforts to re-green cities, especially in lowincome and so-called minority neighborhoods can have paradoxical consequences. For instance, researchers have shown that the development of parks and other greenspaces can increase property values (Eckerd 2011). Unless efforts are taken to manage this effect, it can eventually result in the displacement of marginalized and vulnerable people (Pearsall 2012). Are there alternatives?

A political ecology perspective suggests that the potential of informal greenspace to provide an alternative model to the gentrifying effects of parks and other greenspaces is likely influenced by multiple factors (e.g., social, political, cultural, environmental) (Miller 2016). Three factors are salient: (i) the amount of accessible recreation area potentially provided by informal greenspace; (ii) whether informal greenspace is sociospatially differentiated (e.g. by (dis)advantage); and (iii) whether multiple axes of 
difference such as income and education circumscribe residents' access to, use of, and perceived benefits from the space. The first factor is particularly important.

If IGS is not proximate, residents may be prevented from using it by the same mechanisms that can limit park visitation. If IGS is locally available, but physical barriers, land tenure or management make access difficult, then its potential benefits are unlikely to be realized. Even if IGS is generally accessible, patterns of socio-spatial disadvantage may still circumscribe benefits available to marginalized and vulnerable communities. Axes of difference such as gender, age, (dis)ability, income or education can affect both actual and perceived accessibility, and may render some sites 'off limits'.

\section{Methods: assessing informal greenspace distribution and accessibility}

To examine IGS amount, and interactions between patterns of socio-spatial disadvantage, and its appreciation and use by low-income residents, we draw upon results from a recent cross-national IGS study in Brisbane, Australia and Sapporo, Japan (Rupprecht and Byrne 2014a, Rupprecht et al. 2016). As we have described elsewhere (Rupprecht and Byrne 2014a), these two cities have similarities and differences that lend them well to comparison (Table 1). They provide excellent opportunities for cross-cultural research. Both cities are relatively young (being founded in the $19^{\text {th }}$ century) and they saw most of their growth during the $20^{\text {th }}$ century, especially in the post-second world-war period. Their close geographical size is complemented by a similar urban morphology. They are built around a dense central business district, are situated proximate the coast and upland regions, and are bisected by a central river. These similarities contrast with differences in population density, population growth forecasts, and available greenspace.

While Sapporo has seen rapid growth throughout the second half of the $20^{\text {th }}$ century and currently has a population of about 1.9 million, its population is now stagnating and is predicted to decline in the future. In contrast, Brisbane has a population of around 1 million but is still growing relatively quickly (Table 1). In both cities, formal greenspace consists of networks of over 2,000 public parks, many of them small local parks. Brisbane has 3,290 ha of local parkland ( $32 \mathrm{~m}^{2} /$ capita), whereas Sapporo has 2,345 ha (12.3 $\mathrm{m}^{2} /$ capita) (Table 1). All parks in Brisbane comprise an area of 11,840 ha $\left(115 \mathrm{~m}^{2} /\right.$ capita $)$, while those in Sapporo combine to form an area of 5,508 ha (28.9 $\mathrm{m}^{2}$ /capita). These greenspaces include forested hillsides in the southwest of both cities, providing residents with additional recreation space. However, access to these spaces can be restricted due to bushfires in Brisbane (Queensland Government 2012) and bear sightings in Sapporo (Sapporo Kankyōkyoku Midori No Suishinbu 2013). 
Table 1: Comparison of cities containing the survey areas (Rupprecht and Byrne 2014a)

\begin{tabular}{|c|c|c|}
\hline Characteristics & City of Brisbane (LGA) & Sapporo \\
\hline Founded & 1824, city status 1902 & 1868, city status 1922 \\
\hline Population & $\begin{array}{l}1,089,743(2011)(2031: 1,27 \\
\text { million) }\end{array}$ & $\begin{array}{l}1,936,189(2013)(2030: 1,87 \\
\text { million) }\end{array}$ \\
\hline Area & $1,338 \mathrm{~km}^{2}$ & $1,121.12 \mathrm{~km}^{2}$ \\
\hline Pop. density & $814 / \mathrm{km}^{2}$ & $1,699 / \mathrm{km}^{2}$ \\
\hline Peak density & $>5,000 / \mathrm{km}^{2}$ & $>8,000 / \mathrm{km}^{2}$ \\
\hline Climate & Humid subtropical (Cfa) & Humid continental (Dfa) \\
\hline Industry & $\begin{array}{l}\text { Tourism, resources, retail, } \\
\text { financial services, agriculture } \\
\text { hub, education }\end{array}$ & $\begin{array}{l}\text { Tourism, retail, IT, } \\
\text { agriculture hub, resources, } \\
\text { education }\end{array}$ \\
\hline Greenspace & $\begin{array}{l}\text { Local parks: } 3,290 \text { ha } \\
\left(32 \mathrm{~m}^{2} / \text { capita }\right) \\
\text { All parks: } 11840 \mathrm{ha} \\
\left(115 \mathrm{~m}^{2} / \text { capita }\right)\end{array}$ & $\begin{array}{l}\text { Parks: } 2,345 \text { ha } \\
\left(12.3 \mathrm{~m}^{2} / \text { capita }\right) \\
\text { All greenspace: } 5,508 \text { ha } \\
\left(28.9 \mathrm{~m}^{2} / \text { capita }\right)\end{array}$ \\
\hline $\begin{array}{l}\text { Park area } \\
\text { planned }\end{array}$ & $\begin{array}{l}40 \mathrm{~m}^{2} / \text { capita, minimum } \\
20 \mathrm{~m}^{2} / \text { capita }\end{array}$ & $\begin{array}{l}\text { "No greenspace loss, park } \\
\text { renovation" }\end{array}$ \\
\hline
\end{tabular}

\subsection{Amount of accessible IGS in Brisbane and Sapporo}

To assess the amount of IGS in the dense centers of the two cities, the first author systematically surveyed a 10x10 km grid containing 121 sampling sites of $2,500 \mathrm{~m}^{2}$ per city, drawing upon data recorded in the field and aerial photography. IGS was classified by type (see Figure 1). Accessibility of IGS was classified using a three-level scale, based on the amount of physical or psychological effort necessary to overcome access barriers (Rupprecht and Byrne 2014a). 

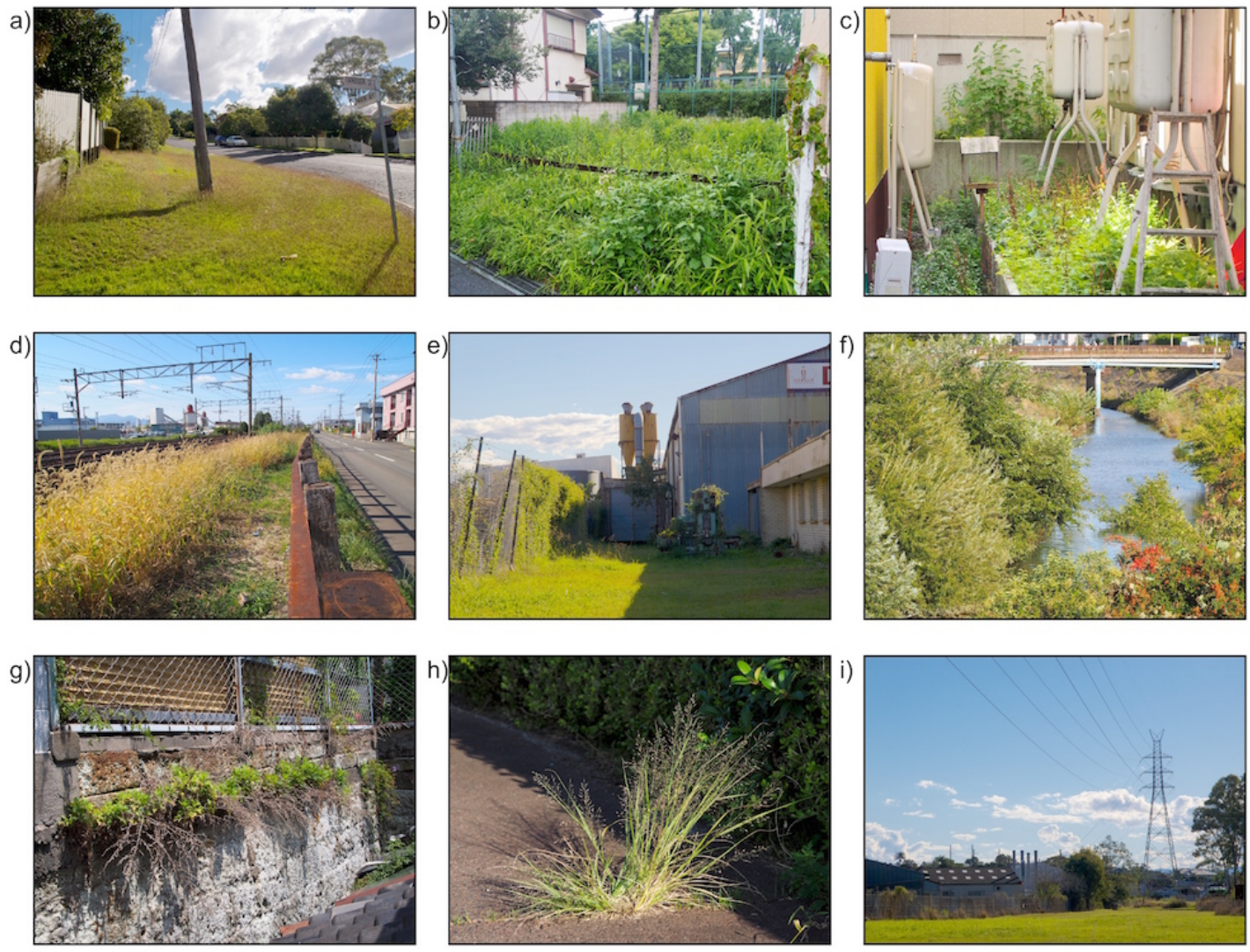

Figure 1 Photographs of informal greenspace types following the IGS typology devised by Rupprecht and Byrne (2014a). (a) Street verge, covered in spontaneous herbal vegetation (Brisbane, Australia); (b) lot, formerly residential with perfunctory access restriction (Tokyo, Japan), (c) gap, space between three buildings with spont. herbal vegetation used by birds (Sapporo, Japan); (d) railway, annual grass verge between rail track and street; (e) brownfield, spont. vegetated industrial space around abandoned factory (Brisbane); $(f)$ waterside, spont. vegetation on banks and deposits in highly modified river (Nagoya, Japan); (g) structural, spont. vegetation growing out of vertical, porous retaining wall (Tokyo); (h) microsite, grass growing spont. growing out of crack in the pavement (Nagoya); (i) powerline, vegetated right of way underneath high voltage powerline (Brisbane). Source: Rupprecht and Byrne (2014a).

\section{Findings: informal greenspace distribution in Australia and Japan}

Our results show that IGS in both cities accounts for a significant area of accessible urban greenspace, about $14 \%$ of total greenspace in the survey areas. Further, informal greenspace is widely distributed throughout both cities (Figure 2), and in both cities over $80 \%$ of IGS appears to be accessible or partly accessible. This suggests IGS may provide a valuable contribution as an alternative greening strategy to limit environmental gentrification.

\subsection{IGS accessibility}

The surveyed area in Brisbane consisted of $6.3 \%$ IGS, while the surveyed area in Sapporo consisted of IGS to $4.8 \%$. Street verges made up over $80 \%$ of IGS in the Brisbane survey area, while vacant lots $(42.2 \%)$ and gaps $(19.2 \%)$ were the two largest IGS types in the Sapporo survey area (Rupprecht and Byrne 2014a). In comparison to formal greenspace (e.g. parks, sports, recreation, and conservation areas) and private greenspace (gardens, shared greenspace, community land, and commercial and industrial greenspace), IGS in Brisbane contributed more than half as much $(6.3 \%)$ as formal greenspace $(11.6 \%)$ and more than one fifth as much IGS than private greenspace $(27.4 \%)$. In Sapporo, the IGS area (4.8\%) was almost a third of formal 
greenspace area (15.4\%) and private greenspace (15.0\%). We found IGS was present in most of the sampling sites in both cities (Figure 2), with the obvious exceptions of sites located in areas with large-scale land use types (e.g. Brisbane river, Mt. Moiwa in the South-West of Sapporo). In Brisbane, 78\% of IGS area was fully accessible, 7\% partially accessible and 15\% not accessible. In Sapporo, the accessible IGS area (68\%) and not accessible area (10\%) was smaller, offset by a larger partially accessible IGS area (21\%) (Rupprecht and Byrne 2014a).

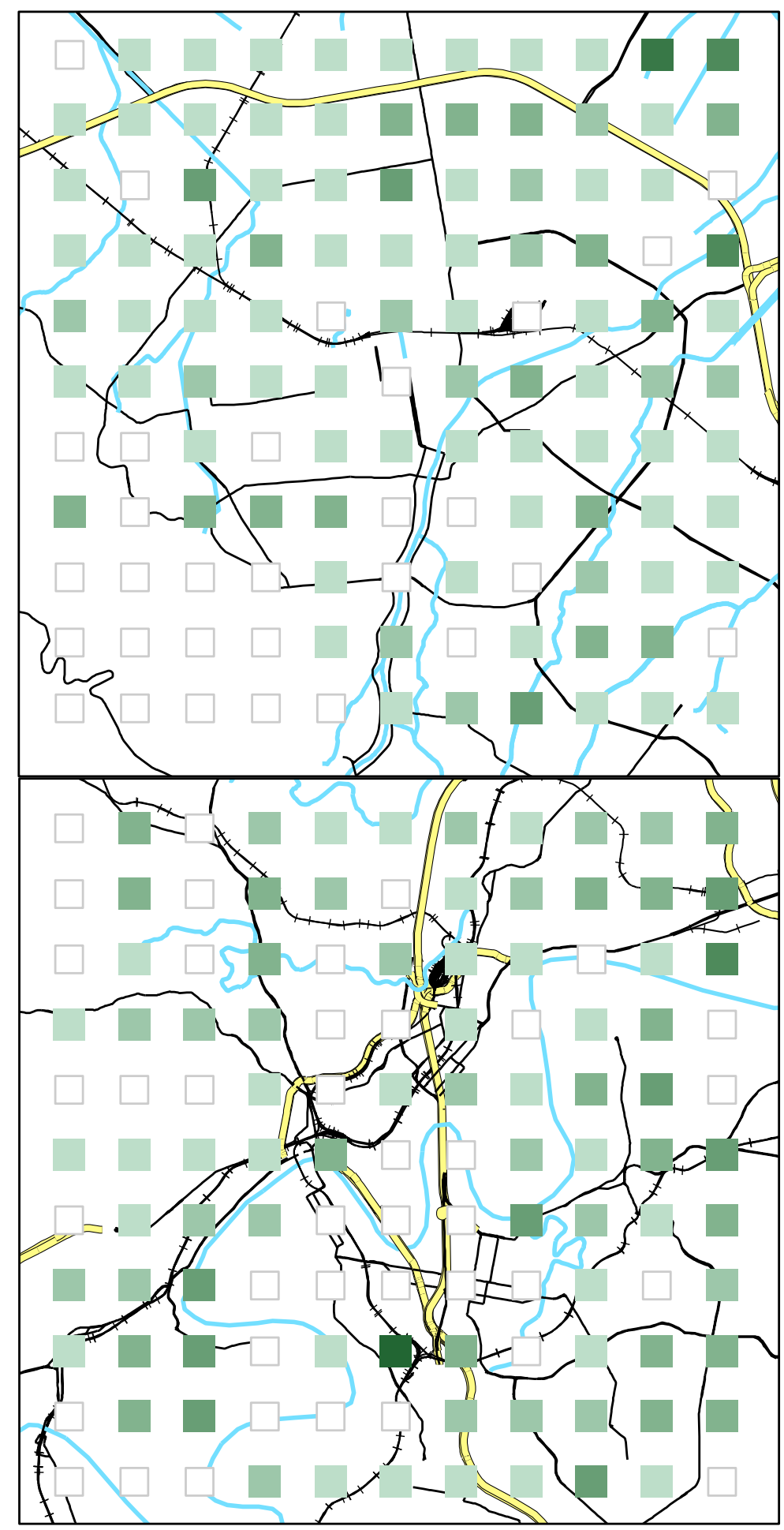

\section{Spatial IGS distribution in Sapporo (top) and Brisbane (bottom) survey areas}

\section{Sampling sites*}

Percent IGS land use

$$
\begin{aligned}
& 0 \% \\
& >0 \%-5 \% \\
& >5 \%-10 \% \\
& >10 \%-20 \% \\
& >20 \%-30 \% \\
& >30 \%-40 \% \\
& >40 \%-50 \% \\
& >50 \%-60 \%
\end{aligned}
$$

\section{Infrastructure}

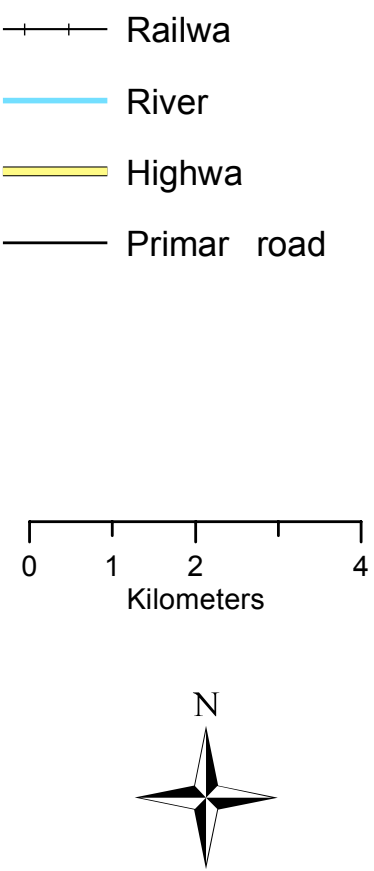

Figure 2Spatial IGS distribution: percentage of IGS per sampling site in Sapporo (top) and Brisbane (bottom). (Rupprecht and Byrne, 2014a) 


\subsection{IGS occurrence and socio-economic (dis)advantage}

To analyze the socio-spatial effects of IGS, we drew upon the results of the IGS survey in Brisbane (Rupprecht et al. 2016) testing for interrelationships between IGS distribution and socio-economic disadvantage. We used the Index of Relative Socioeconomic Advantage and Disadvantage (IRSAD), calculated based on the Australian Bureau of Statistics 2011 Census of Population and Housing (Pink 2013). The IRSAD summarizes variables (related for example to income, education, employment, occupation, housing) that indicate either relative advantage or disadvantage, to rank areas on a continuum from most disadvantaged to most advantaged (Pink 2013). We calculated the IRSAD percentile for each IGS survey site in Brisbane based on the IRSAD percentile of their statistical area (Level 1, Pink 2013). For sites located on two or more statistical areas with different IRSAD percentiles, we adjusted the IRSAD percentile for IGS sites by weighting the contribution of each statistical area percentile by the area it contributed to the IGS site. For example, an IGS site consisting to $50 \%$ each of two statistical areas with percentiles of 50 and 100, the IGS site was given an IRSAD percentile of 75. We then performed non-parametric Spearman rho tests in SPSS (v. 22, OSX) to analyze whether IRSAD percentile was correlated with the percentage of total IGS land use or with the percentage of a particular IGS type on the Brisbane sites.

Our results showed no significant $(\mathrm{p}>0.05)$ correlations between IRSAD percentile and total IGS land use, nor did we find a significant correlation between the IRSAD percentile and any of the different IGS types. This means that IGS was equally distributed between socio-economically advantaged and disadvantaged areas in our survey sites. In contrast, researchers have shown that formal greenspace in Brisbane and other Australian countries is significantly more scarce in low-income areas (AstellBurt et al. 2014). While our result is limited to the 121 sites we surveyed for IGS, it could suggest that IGS is more evenly distributed than formal greenspace. IGS could thus make a valuable contribution to limiting environmental gentrification.

\subsection{IGS use and appreciation - influence of education and income}

To consider how residents view the role of IGS in the local context, we have drawn upon a exploratory letterbox-drop, reply-paid mail-back survey of 1,910 households in Brisbane (valid responses 123; response rate 6.4\%) and 1,980 in Sapporo (valid responses 163; response rate 8.2\%) about IGS (Rupprecht et al. 2015). Questionnaires were only distributed at sites where IGS was located within the $400 \mathrm{~m}$ radius, to maximize potential respondents IGS interaction. The 121 sampling sites were placed on the intersecting lines of a $10 \mathrm{~km}$ by $10 \mathrm{~km}$ grid, centered on the city centers.

In the questionnaire, residents were asked about their IGS perception, evaluation, and use, employing multiple-choice questions and one open comment question. We also included socio-demographic questions (e.g., household income, housing type, respondent age). To analyze the quantitative data, we used SPSS (v. 21, OS X) to perform descriptive and inferential statistical analyses. Initial analyses indicated that the sample data was not normally distributed (P-P plots, skewness and kurtosis tests). We used Kruskal-Wallis and Fisher's Exact tests to analyze a possible influence of respondents' income and level of education on their appreciation and use of IGS. For the qualitative data, derived from respondents' comments in the open response questions, we used content analysis and coding to identify themes present in the text 
(Sproule 2006). Respondents were assigned pseudonyms chosen from popular names during their time of birth in their respective cultures, to protect anonymity.

Our results show that respondent income and level of education had no significant influence $(\mathrm{p}>0.05)$ on their evaluation of IGS in Brisbane or Sapporo (Rupprecht et al. 2015). Respondent income and level of education also had no significant influence on their reported IGS use or frequency as adults or during their childhood or teen age. In contrast, the literature has reported an association between lower respondent income and higher constraints to formal greenspace use, including social barriers (e.g. fear of crime), physical barriers (e.g. lack of transport or cost of transport) and motivational barriers (reduced interest) (Mowen, Payne, and Scott 2005).

Respondents also highlighted the difference between formal and informal greenspace in their open-ended comments. They criticized the rigidity of parks, valuing the flexibility afforded by IGS. For example:

"[IGS]'s informality allows more people to use the space in more and different ways. Its informality echoes the informality of our society in our youth and formative years." (Giorgos, 60, male, Brisbane)

"A neutral zone that belongs to nobody is necessary: left-over room, margins, interstices, space. A life like in the city, where man-made objects are surrounded by nothing but artificial greenspace, is suffocating." (Satoshi, 45, male, Sapporo)

These comments prompt us to consider whether designing and planning greenspace is always desirable, and whether it actually caters to residents needs. They also challenge the notion that planning produces superior outcomes to residents' informal management. Survey respondents recognized that access to greenspace has environmental and intergenerational justice dimensions too:

"Near railway lines people often grow vegetables and flowers and so on. You can see it a lot when riding the train. I think they grow it there because they have no other space." (Yumiko, 60, female, Sapporo)

"I think that there is a clear link between growing up in an area where children can "interact" with their environment, and environmental awareness/compassion, as an adult. I have travelled extensively and I have seen areas where children grow up in high rise apartments, with only infrequent access to a sterile (i.e. unchanging) park, and these have been the areas of the most unnecessary (and widespread) environmental damage." (Thomas, 41, male, Brisbane)

"Today, there's no place for young teenagers to go other than hanging out in front of convenience stores. Even in Doraemon (a very famous Japanese cartoon, Author's note) the children play in vacant lots every day. And parks are so overmaintained there's nothing except a few ants." (Akiko, 42, female, Sapporo)

Respondents' observations suggest that IGS could provide a valuable greenspace resource to residents who are deprived of formal greenspace. While our study results are limited to the respondents from Brisbane and Sapporo, they suggest that IGS could have the capacity to avoid issues associated with environmental gentrification, such as displacement. 
Other studies have found similar results. In his account of the Brooklyn Eastern District Terminal in New York, Campo (2013) for instance, noted how land use planners' efforts to formalize informal greenspaces can alienate their users. Similarly, Qviström (2012) has shown how residents in Gyllin's Garden, Sweden, were opposed the way the traditional planning processes diminished their enjoyment and use of that previously informal space. So what are the alternatives to formalizing liminal and 'derelict' sites such as these?

\section{Problems and possibilities in IGS provision and use: Insights from Japan}

To conclude the chapter, we draw upon insights from three Japanese examples. These examples show how different land tenure arrangements can produce divergent outcomes for residents. The sites were assessed as part of the first author's fieldwork.

\subsection{IGS gardening in Sapporo and Nagoya}

Site 1 is located behind the embankment of Tenpaku River close to its estuary, in the south of Minami Ward, Nagoya, Japan (Figure 3). It is a mixed-use locality of residential and industrial land. Alongside a small road with little traffic, what was originally a storm drain gutter has been filled with soil to form a narrow roadside verge (nature strip). Almost the complete length is used by residents for informal gardening. Plantings include decorative flowerbeds (next to a small factory building), fruit trees and a variety of vegetable gardens (e.g., onions, cabbage, carrots, broccoli). Vegetable gardens show different intensities of use. While some feature casual cultivation, many have improvised fences, raised beds, dry stonewalls, and water collection basins (see Figure 3).

Use of this IGS site is characterized by uncertainty. Site signage shows the space is contested. According to one user, inhabitants of the street have been cultivating this roadside verge for many years (personal communication). Asked about tenure, he said the city is the formal owner of the land, and he noted the informal nature of the residents' activities. He commented that he would have to give up his lot if the city asked him to, but stated that under the circumstances, residents were doing their best with the land. The site also shows evidence of vegetable theft. Some lots have handmade signs that read, "don't take anything", or "somebody is watching". One even featured a commercial "surveillance camera" sign. 

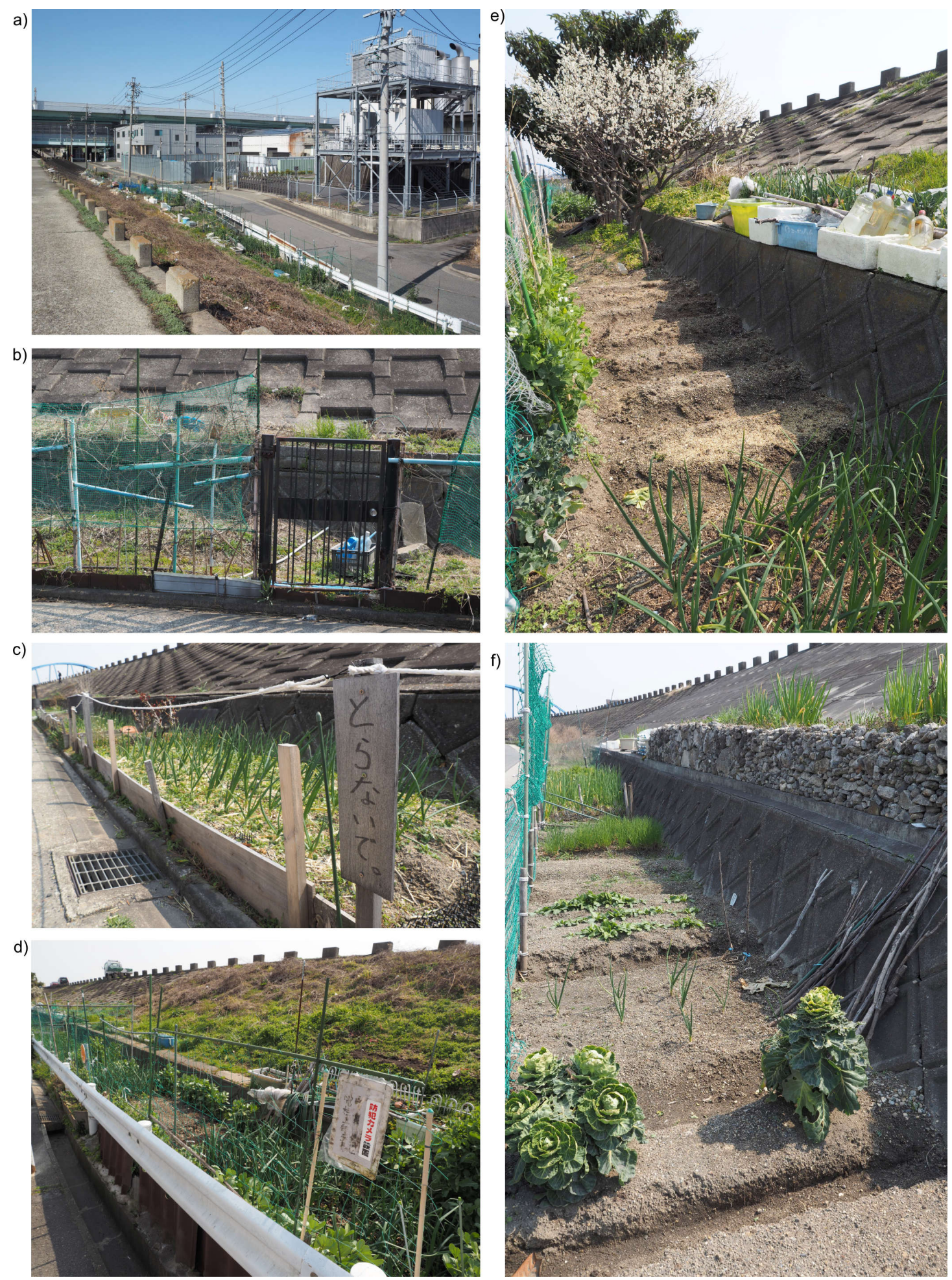

Figure 3 Photographs of site 1, informal roadside IGS garden lots (Minami Ward, Nagoya). (a) View from Tenpaku River embankment over roadside gardens in industrial area. (b) High level of site modification with improvised fences and repurposed entrance door. (c) "Don't take them" - sign to admonish potential vegetable thieves. (d) "Security camera installed" - sign to deter potential vegetable thieves. (e) Planted tree and rainwater collection tools. (f) Fenced lot with dry stonewall.

Site 2 is located on the artificial raised riverbanks of Motsukisamu River in Toyohira Ward, Sapporo, Japan. It is flanked on both sides by medium to high-density residential land use (Figure 4). The site measures about one kilometer in length, and the width varies between two to five meters wide. While spontaneous vegetation covers some 
parts, most of the area is informally gardened. Plantings include a variety of flowerbeds (e.g., tulips, sunflowers) and vegetables (e.g. onions, pumpkins, tomatoes), but also grape vines, which require long-term care and investment. In contrast to the first site, here lots are not demarcated by fences. Because the riverbanks are located about two to three meters below street and housing level, users have installed their own ladders to provide access. Whereas users of the site 1 rely on basins to catch rainwater, gardeners at the second site use a wall drainage system to collect water, via an improvised irrigation system.

This second site is characterized by an ongoing conflict with the city as the official property owner. Not only is there no official use agreement in place to guarantee longterm site access, the city government considers any use of the river banks for agriculture to be a violation of the river law (kasenho $)$. The city has demanded that the residents return the river banks to their former condition, but how the city government intends to enforce this remains unclear. Because the artificial river banks were created to prevent flooding, which the Motsukisamu river was prone to do before its modification (Wikipedia, “望月寒川” (motsukisamugawa) 2014), flash floods may be a matter of concern for city officials, and could be dangerous for IGS users.

Site 3 is located in a power transmission corridor in Minami Ward, Nagoya, Japan, about 500 meters from site one. It is flanked on both sides by small, one-way residential streets and medium to high-density residential land use (Figure 5). The site measures about 600 meters long and ten meters wide. Besides three powerline pylons and a small area with gravel used for community purposes (e.g., festivals, trash collection), the site is divided into dozens of small allotment gardens (Figure 5). Plantings include decorative flowerbeds, vegetable patches (e.g., onions, cabbage, radish, carrots), fruit trees (e.g., clementine and peach trees), and ornamental trees (e.g., groomed pine trees). In contrast to site one, the allotment gardens show a constant, high level of modification and resource investment. Lots have been secured with fences where the power line corridor meets the street, but rarely between two patches. Users have repurposed pots, ski poles, umbrellas, office chairs and other equipment for gardening purposes.

In contrast to the other two sites, use of this informal allotment garden is characterized by long-term stability due to an agreement with the property owner, the local power utility Chubu Electric Power, which is a publicly owned corporation. Although still an informal greenspace in management and use, the agreement formalizes usufruct access. According to one user, this arrangement has allowed residents to garden the land free of charge (personal communication). In return, the residents have agreed to keep vegetation "orderly" and below a specified height to prevent it from reaching the overhead powerline. The agreement is between the utility and the local neighborhood associations (chōnaikai), which manage allocation to the local residents. Gardens are generally not protected against theft in any way, a marked difference from the roadside verge gardens. Possibly the semi 'official' status of the allotment gardens is enough to deter potential thieves. Our informant also showed clear pride in her garden, vegetables, and flowers. She had none of the insecurity and uncertainty about the future of her garden felt by informants from the other sites, suggesting this case offers a potential model for other cities. 

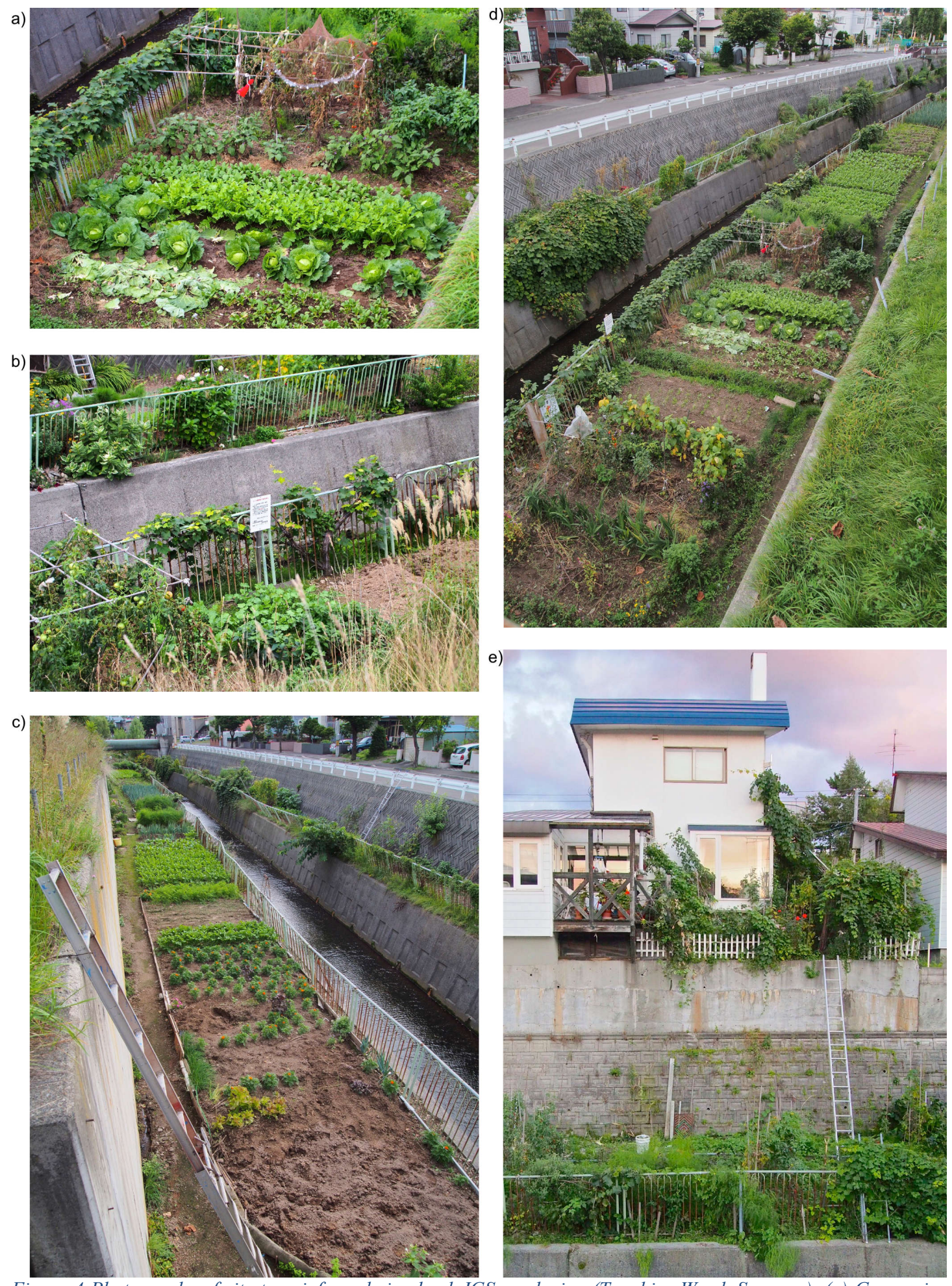

Figure 4 Photographs of site two informal riverbank IGS gardening (Toyohira Ward, Sapporo). (a) Grape vine using the existing fence next to a variety of vegetable patches. (b) Gardening-prohibited sign placed by city government inside vegetable patches. (c) Ladder providing easy access to riverbank site. (d) Vegetable patches continuing along the side of Motsukisamu River. (e) Riverbank garden used as extension to private garden, with ladder for easy access. 

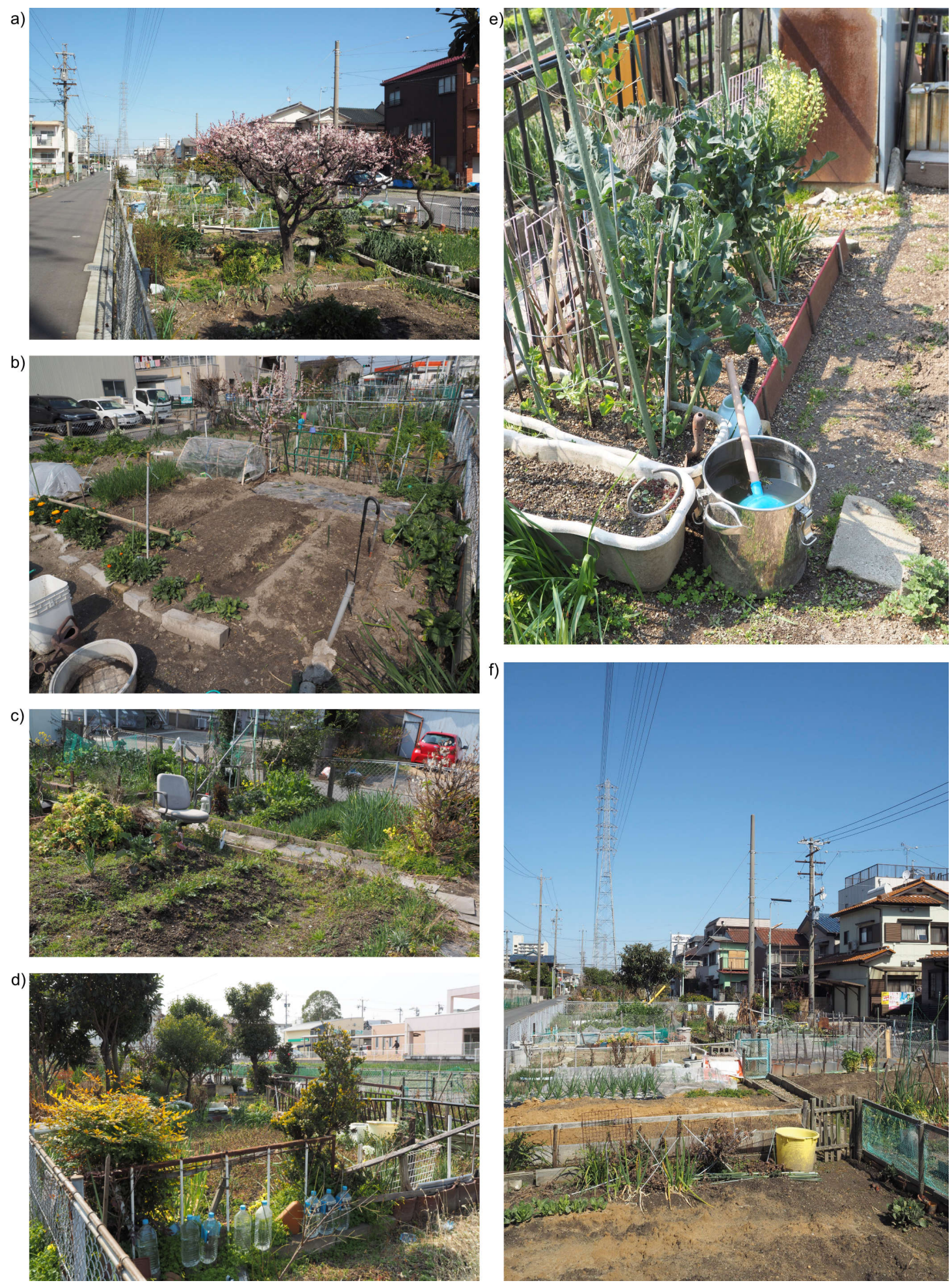

Figure 5 Photographs of site three, allotment gardens under powerline transmission corridor (Minami Ward, Nagoya). (a) Peach tree in allotment gardens flanked by small, residential one-way roads. (b) Allotment gardens with improvised tools (ski poles, umbrella core). (c) Office chair repurposed as place of rest. (d) Trees and water storage in allotment gardens. (d) Vegetable patches and cooking pot repurposed as water cask. (f) Low height, interlot fencing without warning signs or other anti-theft measures. 


\subsection{The role of tenure and management}

All three of the above sites provided local residents with recreational and economic benefits without producing any obvious signs of environmental gentrification. The small scale of the gardening activities and their informality likely play a role, but may also limit the benefits for residents. Small lot size, and the residents' knowledge that any investment of time and resources is somewhat precarious, may prevent extensive embellishment - allowing gardeners to exist somewhat 'below the radar' of authorities. Here residents have found ways to derive benefits from IGS without financial or organizational assistance from authorities, and have seemingly avoided displacement because the small scale and informal qualities of their embellishments has not changed neighborhood character or amenity. However, this success comes at the price of longterm stability, limited space, and potential conflict with thieves and/or property owners.

We argue that the crucial difference between these three sites and places where environmental gentrification has occurred, such as the New York High Line in New York, can be understood as a function of design and management. The High Line was completely redesigned from its industrial origin, and is a professionally maintained greenspace, with substantial running costs. It caters to visitors and new residents drawn to its visual appeal and 'hipness'. Millington (2015) offers a compelling critique of the High Line as 'a neoliberal green space, one that traded luxury development for green space provisioning'. And he cautions against viewing informal green space as intrinsically opposed to capitalist politics, noting how its 'weediness' can be appropriated to undergird a 'narrative of ecological sustainability' (Millington 2015, 12), which depoliticizes and dehistoricizes the space, paving the way for investment that masks the violence and marginalization typical of communities battling brownfield redevelopment.

The Japanese sites we have discussed above were not designed by professionals (e.g. landscape architects). They are vernacular spaces, shaped through day-to-day use and by the aesthetic ideals and culinary preferences of their users (Berthelsen 2015). Running costs are modest. For site three, although the neighborhood associations allocate lots, and the residents maintain them, the utility does not charge a fee. Consequently there is no 'windfall gain' to property owners. External private capital investment is not required to create an informal greenspace like these. The marginal character of these sites - a road verge, a drainage floodplain and a powerline easement - also renders them less attractive to speculative property development. Environmental gentrification is therefore less likely. 


\section{Conclusion: implications for policy, planning and geography?}

In this chapter we have examined how using informal greenspace (IGS) in Japan and Australia to meet residents' needs could function as an anti-gentrification strategy. We found that IGS in Sapporo and Brisbane did not exhibit the patterns of disadvantage common for public parks. Instead, these spaces were co-created by residents as designers, managers and users. This raises important questions for urban policy and planning and private property management.

Many local governments grapple with fiscal constraints in providing greenspace. Research shows that public greenspace provision can displace poorer residents, due to rising property values. Informal greenspaces, characterized in the literature as 'liminal', 'ambivalent', or 'overlooked', have tended to be ignored as an urban greening alternative (Rupprecht and Byrne 2014b; Jorgensen and Tylecote 2007). Planners and developers lack of interest in such spaces opens the possibility for residents to appropriate them, with or without the cooperation/consent of their formal owners, and to modify them according to residents' specific needs. This raises the question of whether we could leave some greenspace creation, design and management fully in the hands of local residents? And if so, what role should be played by planners and private property owners?

Planners might begin by assisting residents to identify and reduce barriers to IGS use, such as removing fences around vacant lots (Hayashi, Tashiro, and Kinoshita 1999) or by cataloguing and making public soil contamination (McClintock 2012). Planners could also provide residents with information about the availability of IGS in their neighbourhoods (e.g. via an IGS map or app). For instance, 596acres, a New York NGO, maps publically owned vacant land and helps local residents to convert it to community gardens. Some of the money saved by avoiding costly design and maintenance of formal parklands could be redirected to provide residents with resources to start their own community-led projects. Private property owners could follow the example of the Japanese utility and enter into usufruct agreements with local residents, without harming management and occupancy rights.

In this chapter we have offered some insights into the accessibility and use of IGS in Australia and Japan, but more work is required. Quantitative methods should be further applied to investigate the socio-spatial distribution of IGS in different cities, and the socio-demographic profile of IGS users. This would assist in determining if IGS accessibility is correlated with patterns of social (dis)advantage. In-depth interviews, focus groups, participant observation, ethnography or participant photography should be undertaken, to better understand the motivations driving IGS users (e.g., lack of access to gardens or formal greenspace, use restrictions, proximity), the difficulties they face (e.g., conflict with property owner, theft), and what possibilities exist to employ IGS as an anti-gentrification strategy more widely. Our research suggests that IGS has considerable potential to play a key role in urban greening. 


\section{Acknowledgements}

An earlier version of this paper was presented at the American Association of Geographers Annual Meeting 2015 in Chicago. We thank the session organizers and participants for their helpful feedback on this paper. We also thank Yumi Nakagawa and Kumiko Nakagawa for their help with fieldwork and data collection, and all respondents for participating in this study. Parts of this work were supported by the Japan Society for the Promotion of Science (grant number 24658023), by Griffith University, and by the FEAST project (No. 14200116), Research Institute for Humanity and Nature (RIHN). 


\section{References}

Anguelovski, I. 2016. From Toxic Sites to Parks as (Green) LULUs? New Challenges of Inequity, Privilege, Gentrification, and Exclusion for Urban Environmental Justice. Journal of Planning Literature, 31(1), 23-36.

Astell-Burt, T., Feng, X., Mavoa, S., Badland, H. M., Giles-Corti, B. 2014. Do LowIncome Neighbourhoods Have the Least Green Space? A Cross-Sectional Study of Australia's Most Populous Cities. BMC Public Health 14 (1): 292. doi:10.1186/1471-2458-14-292.

Berthelsen, C. 2015. “Tokyo's Non-Intentional Landscape.” Accessed July 21. http://non-intentional-landscape.a-small-lab.com/?og=1.

Brink, E., et al. 2016. Cascades of green: a review of ecosystem-based adaptation in urban areas. Global Environmental Change, 36, 111-123.

Byrne, J. 2012. When green is White: The cultural politics of race, nature and social exclusion in a Los Angeles urban national park. Geoforum, 43(3), 595-611.

Byrne, J., et al. 2016. Could urban greening mitigate suburban thermal inequity?: the role of residents' dispositions and household practices. Environmental Research Letters, 11(9), 095014.

Byrne, J. and Wolch, J. 2009. Nature, race, and parks: past research and future directions for geographic research. Progress in Human Geography, 33(6), 743765.

Campo, D. 2013. The Accidental Playground. New York: Fordham University Press.

Checker, M. 2011. Wiped out by the "greenwave": Environmental gentrification and the paradoxical politics of urban sustainability. City \& Society, 23(2), 210-229.

Curran, W. and Hamilton, T. 2012. Just green enough: contesting environmental gentrification in Greenpoint, Brooklyn. Local Environment, 17(9), 1027-1042.

Eckerd, A. 2011. Cleaning up without clearing out? A spatial assessment of environmental gentrification. Urban Affairs Review, 47(1), 31-59.

Fitzgerald, J. and Laufer, J. 2016. Governing green stormwater infrastructure: the Philadelphia experience. Local Environment, 1-13.

Hayashi, M., Tashiro, Y., Kinoshita, T., 1999. A Study on Vacant Lots Enclosed by Fences in Relation to Urbanization. Landscape Research Japan 63, 667-670. doi:10.5632/jila.63.667

Kern, L. 2015. From toxic wreck to crunchy chic: Environmental gentrification through the body. Environment and Planning D: Society and Space, 33(1), 67-83.

Lafontaine-Messier, M., Gélinas, N. and Olivier, A. 2016. Profitability of food trees planted in urban public green areas. Urban Forestry \& Urban Greening, 16, 197-207.

Lin, B., Meyers, J. and Barnett, G. 2015. Understanding the potential loss and inequities of green space distribution with urban densification. Urban Forestry \& Urban Greening, 14(4), 952-958.

Jorgensen, A., and Tylecote, M. 2007. Ambivalent Landscapes-wilderness in the Urban Interstices. Landscape Research 32 (4): 443-462. doi:10.1080/01426390701449802.

McClintock, N. 2012. Assessing Soil Lead Contamination at Multiple Scales in Oakland, California: Implications for Urban Agriculture and Environmental Justice. Applied Geography $35 \quad$ (1-2): 460-473. doi:10.1016/j.apgeog.2012.10.001.

Miller, J. T. 2016. Is urban greening for everyone? Social inclusion and exclusion along the Gowanus Canal. Urban Forestry \& Urban Greening, 19(1), 285-294. 
Millington, N. 2015. From urban scar to 'park in the sky': terrain vague, urban design, and the remaking of New York City's High Line Park. Environment and Planning A, 47(11), 2324-2338.

Mowen, A. J., Payne, L. L., Scott, D. 2005. Change and Stability in Park Visitation Constraints Revisited. Leisure Sciences 27 (2): 191-204. doi:10.1080/01490400590912088.

Nohl, W. 1990. Gedankenskizze Einer Naturästhetik Der Stadt. [Thought sketch of a natural aesthetic of the city, in German] Landschaft Und Stadt 22 (2): 57-67.

Pearsall, H. 2010. From brown to green? Assessing social vulnerability to environmental gentrification in New York City. Environment and Planning C: Government and Policy, 28(5), 872-886.

Pearsall, H. 2012. Moving out or moving in? Resilience to environmental gentrification in New York City. Local Environment, 17(9), 1013-1026.

Pink, Brian. 2013. Socio-Economic Indexes for Areas (SEIFA) 2011. Australian Bureau of Statistics.

Qviström, M. 2012. Taming the Wild: Gyllin's Garden and the Urbanization of a Wildscape. In Urban Wildscapes, edited by Jorgensen, A. and Keenan, R., 187200. Abingdon: Routledge.

Quastel, N. 2009. Political ecologies of gentrification. Urban Geography, 30(7), 694725.

Queensland Government, Department of National Parks Recreation Sport and Racing. 2012. QPWS Monitors Fire near Brisbane's D'Aguilar National Park. Department of National Parsk, Recreation, Sport and Racing. http://www.nprsr.qld.gov.au/mediareleases/2012-12-qpws-monitors-fire.html.

Rupprecht, C. D. D. and Byrne, J. A. 2014a. Informal urban green-space: comparison of quantity and characteristics in Brisbane, Australia and Sapporo, Japan. PloS one, 9(6), e99784.

Rupprecht, C. D. D. and Byrne, J. A. 2014b. Informal urban greenspace: a typology and trilingual systematic review of its role for urban residents and trends in the literature. Urban Forestry \& Urban Greening, 13(4), 597-611.

Rupprecht, C. D. D., et al. 2015. Informal urban green space: A trilingual systematic review of its role for biodiversity and trends in the literature. Urban Forestry \& Urban Greening, 14(4), 883-908.

Rupprecht, C. D. D., Byrne, J. A., Ueda, H., Lo, A. Y., 2015. 'It's real, not fake like a park': Residents' perception and use of informal urban green-space in Brisbane, Australia and Sapporo, Japan. Landscape and Urban Planning 143, 205-218. doi:10.1016/j.landurbplan.2015.07.003

Rupprecht, C. D. D, Byrne, J. A. and Lo, A. Y. 2016. Memories of vacant lots: how and why residents used informal urban green space as children and teenagers in Brisbane, Australia, and Sapporo, Japan. Children's Geographies, 14(3), 340355.

Rutt, R. L. and Gulsrud, N. M. 2016. Green justice in the city: A new agenda for urban green space research in Europe. Urban Forestry \& Urban Greening, 19, $123-$ 127.

Sapporo Kankyōkyoku Midori No Suishinbu. 2013. Bear Sighting Information [in Japanese]. City of Sapporo.

http://www.city.sapporo.jp/kurashi/animal/choju/kuma/syutsubotsu/index.html 
Shackleton, C. M. and Blair, A. 2013. Perceptions and use of public green space is influenced by its relative abundance in two small towns in South Africa. Landscape and Urban Planning, 113, 104-112.

Sister, C., Wolch, J. and Wilson, J. P. 2010. Got green? Addressing environmental justice in park provision. GeoJournal, 75(3), 229-248.

Sproule, W. 2006. Content Analysis. In Social Research Methods: An Australian Perspective, edited by Maggie Walter, 114-133. Oxford University Press.

Sreetheran, M. and van den Bosch, C. C. K. 2014. A socio-ecological exploration of fear of crime in urban green spaces-A systematic review. Urban Forestry \& Urban Greening, 13(1), 1-18.

Wikipedia, “望 月 寒 川 .” [motsukisamugawa, in Japanese] 2014. https://ja.wikipedia.org/w/index.php?title=\%E6\%9C\%9B\%E6\%9C\%88\%E5 $\%$ AF\%92\%E5\%B7\%9D\&oldid=53380229.

Wolch, J. R., Byrne, J. and Newell, J. P. 2014. Urban green space, public health, and environmental justice: The challenge of making cities 'just green enough'. Landscape and Urban Planning, 125, 234-244. 